Revista Água Viva

ISSN 1678-7471

\title{
MISS FURY: A PRIMEIRA SUPER-HEROÍNA DE AUTORIA FEMININA ${ }^{1}$
}

MISS FURY: THE FIRST COMIC-BOOK SUPERHEROINE CREATED BY A FEMALE COMIC BOOK ARTIST

\author{
Jaqueline dos Santos Cunha ${ }^{2}$
}

Recebido em: 03 dez. 2019.

Aceito em: 29 mar. 2020.

DOI: 10.26512/aguaviva.v5i1.28429

RESUMO: O presente trabalho discute sobre as rupturas e as continuidades no que toca à representação dos estereótipos femininos na produção quadrinística estadunidense Miss Fury (1941 - 1952), concebida como a primeira super-heroína de autoria feminina. Criação artística de June Tarpey Mills (1912, 1988), Miss Fury foi lançada na ocasião da Segunda Guerra Mundial. Neste momento de transformações sociais e culturais experimentado pelos EUA na metade do século XX, as mulheres foram levadas a contribuir com sua mão de obra nos mais variados cargos, inclusive nas forças armadas e na produção de histórias em quadrinhos. Desse modo, as histórias em quadrinhos, seguindo uma retórica de guerra, funcionavam como uma espécie de propagada do tipo de mulher que os Estados Unidos precisavam para aquele momento. É este papel que a referida super-heroína representa.

Palavras-chave: Representação. Super-heroína. Autoria feminina.

\begin{abstract}
The study discusses the ruptures and continuities in the representation of female stereotypes in the American comic book, Miss Fury (1941 - 1952), which featured the first superheroine of female authorship. In the US during World War II, a period of social and cultural transformation, women were encouraged to take jobs in all fields formerly occupied by men, including in the armed forces and in the comic book industry. Contributing to male displacement, comic books functioned as a sort of propaganda depicting the kind of woman the United States needed at that moment. It is the willingness to accept new roles and take advantage of serendipitous circumstances that the superheroine in Miss Fury represents.
\end{abstract}

Keywords: Representation. Superheroine. Female authorship.

\footnotetext{
${ }^{1} \mathrm{O}$ presente estudo é uma versão atualizada de um dos capítulos de dissertação que foi apresentado no Programa de Pós-Graduação em Estudos da Linguagem, curso de Mestrado em Estudos da Linguagem da Universidade Federal de Goiás - Regional Catalão em 2016.

${ }^{2}$ Pesquisadora de Histórias em Quadrinhos, é mestra em Estudos da Linguagem pela Universidade Federal de Goiás - Regional Catalão (2016), graduada em Letras Português/Inglês pela Universidade Estadual de Goiás Unidade de Inhumas (2007) e integrante da Associação de Pesquisadores de Arte Sequencial (ASPAS). E-mail: jqln.cunha@gmail.com
} 


\section{INTRODUÇÃO}

É amplamente difundido que o surgimento do gênero quadrinístico super-herói (COOGAN, 2006) é marcado pelo nascimento de Superman, produto artístico dos quadrinistas Jerry Siegel e Joe Shuster, publicado na Action Comics \#1 da Detective Comics em junho de 1938. Neste tipo de produção, as mulheres eram quase sempre belas vítimas indefesas que serviam frequentemente como iscas para atrair o destemido super-herói para uma armadilha (MADRID, 2010, p. V).

Representações femininas desta sorte foram durante muito tempo a fórmula que parecia agradar a um grande número de artistas, editores e consumidores homens heterossexuais. O que ainda não foi problematizado a contento é o fato de que as dinâmicas sociais e os interesses mercadológicos e políticos da era dourada dos super-heróis tornaram possível a crescente participação feminina na produção, representação e recepção de histórias em quadrinhos. Essa reparação se tornou o objeto de reflexão de pesquisadoras e quadrinistas mulheres em todo o mundo.

É neste cenário de relativa abertura para o maior envolvimento de mulheres quadrinistas que a obra que procuro destacar se insere. Miss Fury, idealizada e desenhada por June Tarpey Mills (doravante Tarpé Mills), foi a primeira super-heroína inteiramente criada por uma mulher. A super-heroína antecedeu até mesmo a Mulher Maravilha e alcançou relativo sucesso tanto no mercado estadunidense quanto no mercado internacional.

Nesse trabalho tentarei analisar, sem qualquer pretensão de esgotar as discussões, a super-heroína Miss Fury. Discutirei em que medida ela subverte o modelo estabelecido de produção de quadrinhos de super-heróis e as representações femininas presentes na obra.

\section{O nascimento da glamorosa super-heroína de Tarpé Mills}

Embora Miss Fury não tenha sido historicamente a primeira super-heroína norteamericana, foi a primeira a ser criada, roteirizada e desenhada por uma mulher, Tarpé Mills (1912-1988). Os traços artísticos de Mills eram, e as imagens oportunamente comprovarão, promissores. Ao que parece, a artista aproximou suas profissões anteriores, a de modelo e ilustradora de moda, da execução das personagens tanto femininas quanto masculinas. Em 
virtude disso, a preocupação com o requinte e o glamour estava sempre presente, seja em se tratando de mocinhas/os ou de vilãs/vilões (ROBBINS, 2013, p. 67).

Em seis de abril de 1941, os leitores dos jornais que tinham parceria com a Bell Sydicate passaram a mergulhar no mundo de aventuras e glamour da jovem Marla Drake que, ao vestir sua indumentária de leopardo preto, dava vida à super-heroína nominada Miss Fury. Originalmente, ela apareceu nos jornais sob o título Black Fury, mas, a partir da $37^{\mathrm{a}}$ tirinha, no domingo 14 de dezembro de 1941, o título da produção foi alterado definitivamente para Miss Fury. A história de origem de Miss Fury difere da de muitos outros/as super-heróis/superheroínas. Ao contrário daqueles/as que lançavam mão de uma indumentária e uma identidade secreta com o fito de socorrer ao próximo ou à nação, Marla se entregava a uma série de aventuras das quais não escolheu espontaneamente participar. Elas apareceram quase casualmente à sua porta e sua iniciativa de enfrentá-las se devia ao fato de Marla ser uma mulher forte e destemida.

A super-heroína em questão não é uma divindade, não veio de outro planeta, não sofreu com os efeitos de nenhum experimento químico, não tem acesso a tecnologias especiais e também não passou por nenhuma mutação genética. Ela sequer possui superpoderes. Trata-se, na verdade, de uma jovem socialite cujas únicas preocupações eram participar de festas e romances, sem nenhuma vocação heroica ou trauma capaz de torná-la uma super-heroína. Em um momento de sua vida, ao se preparar para uma festa à fantasia, Marla recebeu a ligação de uma amiga, Alice, informando que outra pessoa, Carol, usaria fantasia idêntica à dela. Descontente, Marla rasgou toda a sua fantasia decidida a não participar daquele evento. Francine, sua prestativa empregada, sugeriu que Marla vestisse a pele negra de leopardo que o tio havia deixado à jovem. A referida pele de leopardo havia pertencido a uma médica-bruxa que a usava em cerimônias religiosas em alguma região da África. A origem daquela pele causava receios na jovem socialite. Mesmo assim, ela decidiu usá-la a fim de participar da festa à fantasia. Interessada em se divertir, Marla acreditava: "Pelo menos não haverá mais ninguém usando a mesma coisa!” (M.F1³ , 2013, p. 24, tradução minha) ${ }^{4}$.

\footnotetext{
${ }^{3}$ As produções quadrinísticas da super-heroína Miss Fury utilizadas nas análises da dissertação são resultado de um relançamento da editora IDW Publishing, com o suporte da quadrinista norte-americana Trina Robbins. Tratase das produções compreendidas entre 1941 - 1949 que foram publicadas nos anos 2012 e 2013, o trabalho foi organizado cronologicamente, mas nem todas as tirinhas foram encontradas e muitas também não apresentam as datas originais. Trina Robbins usou como justificativa o fato de que na época das produções não havia ainda preocupações no sentido de preservar as informações de maneira acurada. Somente em setembro de 2018, um grupo de colecionadores estadunidenses conseguiu recuperar e organizar os dois anos de produção que faltavam. $\mathrm{O}$ trabalho ainda não foi publicado, mas tive acesso aos arquivos graças à disponibilidade dos colecionadores envolvidos no projeto Miss Fury Restauration Project.

4 "At least no one else will be wearing the same thing!"
} 
No caminho para a festa e trajada com a pele vinda da África, Marla ouve pelo rádio um alerta sobre um assassino fugitivo. No mesmo instante, seu carro é abordado por uma pessoa armada. A jovem pensa se tratar do criminoso e, no ímpeto de se defender, entra numa disputa corporal e o imobiliza. Somente quando tenta reanimá-lo percebe o equívoco, pois se tratava, na realidade, do detetive Dan Carey. Antes de se recuperar do choque, o verdadeiro criminoso aparece e Marla novamente se vê obrigada a usar as "armas" que tem para se defender. Desacordados, detetive e assassino são algemados juntos e Marla parte à procura de um médico para prestar socorro aos homens.

Temerosa com a possibilidade de um escândalo, Marla desiste definitivamente de ir à festa e volta para casa desejando que o caso não atinja proporções maiores e que ninguém faça qualquer conexão entre o ocorrido e sua pessoa. Na manhã seguinte, o nome de Marla não aparece nos jornais, mas a menção ao seu feito e à sua indumentária foi inevitável. Nascia aí a Black Fury, como Miss Fury foi originalmente nominada.

$\mathrm{Na}$ manhã posterior ao incidente, Marla recebe a visita desesperada da amiga Grace James Dana. A jovem senhora, esposa de Jim Dana, promotor recentemente nomeado, estava sendo chantageada por Miguel Rico. O chantagista tinha em seu poder cartas forjadas que evidenciariam a existência de um romance entre ele e Grace. A exposição de uma provável traição abalaria tanto o casamento da senhora James Dana quanto a imagem de Jim, seu marido. Em virtude das naturalizações sociais no que se refere às relações conjugais, a traição masculina poderia até ser vista como aceitável, um exercício de sua virilidade. Contudo, a traição feminina, além de colocar em xeque a virilidade do marido traído, era compreendida como uma evidência da amoralidade da mulher que deve se manter fiel. Por esse motivo, a jovem solicitou à Marla dinheiro emprestado para tentar silenciar o mau-caráter.

Destemida e determinada a ajudar a amiga, Marla decide acompanhar a jovem senhora ao encontro combinado com Miguel Rico para pagar o chantageador. A socialite finge interesse por Miguel Rico e marca um encontro para a mesma noite na mansão dela - note-se que Marla é uma socialite, membro de uma classe social privilegiada. A jovem estava decidida a roubar as cartas de Rico e, para tanto, faz planos com sua empregada para fazer com que o cafajeste a aguarde na mansão enquanto ela vasculha o apartamento dele na tentativa de encontrar as cartas forjadas.

\footnotetext{
${ }^{5}$ Miss Fury não é uma super-heroína armada, ela sempre procura fazer uso de sua força, habilidades acrobáticas e inteligência em primeira instância.
} 
O plano de Marla teria sido bem-sucedido se a baronesa Erica Vam Kampf, considerada a maior vilã das produções de Tarpé Mills (ROBBINS, 2012, p. 09), também não estivesse à procura de documentos na casa de Miguel Rico e as duas não tivessem sido surpreendidas por Miguel Rico, que regressava para pegar a carteira que havia esquecido. Ele percebe a presença de Miss Fury, que ainda é nominada na tirinha por Black Fury, e, por associá-la erroneamente à baronesa Erica Vam Kampf, ele a ataca impiedosamente. Nesse incidente, Rico acaba sendo ferido por um tiro da baronesa, que sai do ambiente sorrateiramente, sem ser notada por nenhum dos dois. Já Miss Fury sai desnorteada, sem entender de onde veio o tiro que acertou Miguel Rico. No ímpeto de abandonar o carro e se livrar da fantasia, uma vez que toda cidade estava em alerta à procura de Miss Fury, Marla entra sorrateiramente numa cobertura na tentativa de roubar uma roupa. Ela retira a pele e a esconde em um vaso no terraço da cobertura que, coincidentemente, estava sendo ocupada pela baronesa Erica. A partir deste ponto, as vidas de Marla, da baronesa Erica, do general Bruno, outro vilão nazista, e do detetive Daniel Carey passam a se cruzar com maior frequência ao longo dos dez anos de Miss Fury.

Todas as coincidências, ou aventuras e desventuras, descritas nesta produção quadrinística são interpretadas por Marla e, posteriormente, por um amigo brasileiro, o índio Albino Jo, como sendo desencadeadas pelo uso da pele de leopardo que acreditavam ser amaldiçoada e capaz de exercer influências negativas na vida de quem a usasse. No entanto, as aparentes evidências da influência da pele nos feitos da Miss Fury são ignoradas pela própria estratégia narrativa da quadrinista, que usa esparsamente a vestimenta de pele de leopardo e trata com maior frequência das aventuras de Marla Drake, sem fantasia.

\section{Miss Fury: espelho das contradições da década de 1940}

O movimento sufragista, a Grande Depressão e a iminência da Segunda Grande Guerra (1939-1945) configuraram as relações sociais e, no interior delas, os papéis da mulher nos contextos privados e públicos. Desse momento em diante, em virtude das circunstâncias sociais e da luta feminina, as mulheres passaram a ocupar os espaços públicos, seja através do voto, seja através do trabalho remunerado. Contudo, essa nova realidade não diluiu as assimetrias de gênero, já que no mundo do trabalho as mulheres eram desvalorizadas em relação aos homens e na política institucional ainda eram sub-representadas.

Considerando esses aspectos, acrescento que, embora as mulheres estivessem desempenhando funções que transcendiam o contexto doméstico, é notório que suas 
performances continuavam a ser, em certa medida, desvalorizadas, reguladas e vigiadas por instituições mantenedoras dos valores sociais. Nesse sentido, os produtos da indústria cultural de massa foram grandes influenciadores na criação de arquétipos femininos que transitavam entre os modelos tradicionais de mulher e os de "nova mulher" (EWEN, 2001, p. 159). De tal modo, as mulheres que desempenhavam funções de trabalho fabril, por exemplo, eram incentivadas a cumprirem certos protocolos e a continuarem valorizando a vaidade/feminilidade, mesmo quando estivessem realizando trabalho duro (PEISS, 2011). Contudo, essa experiência de liberdade profissional e pessoal, mesmo que aparentemente controlada e manipulada, contribuiu para um maior afrouxamento das tradições e possibilitou ainda o significativo engajamento feminino nas lutas feministas que ganharam força principalmente a partir da década de 1960.

É importante mencionar que no período da produção das histórias em quadrinhos Miss Fury a corrente de pensamento predominante era baseada na ideia de um sujeito sociológico (HALL, 2006, p. 10). Embora essa concepção de sujeito sociológico não descartasse a ideia da interferência cultural na formação do sujeito/identidade, acreditava-se que havia um núcleo identitário, uma essência interior que determinaria a identidade das pessoas. Em decorrência desse pensamento, as/os feministas e as/os simpatizantes do feminismo da época acreditavam que a igualdade pela qual a mulher lutava seria um benefício para toda a humanidade, uma vez que a mulher é, em essência, amor, enquanto o homem é guerra (LEPORE, 2014). Sobre essa leitura de mundo e dos gêneros, Tarpé Mills disse numa entrevista em 1945 que "se todas as mulheres do mundo se juntassem, não haveria mais guerras" (apud ROBBINS, 2013, p. 8, tradução minha $)^{6}$; Marston, criador da Mulher Maravilha, também era um defensor da ideia de uma essência feminina que estava em afinidade com a ideia de amor, paz e sensibilidade. Em outras palavras, muitos dos que defendiam maiores liberdades para as mulheres partiam do entendimento de que a essência afetiva do ser feminino favoreceria uma nova ordem social e política.

Os desdobramentos das alterações sociais, as primeiras conquistas da luta originada pela "primeira onda feminista" e as necessidades de mão de obra feminina dos EUA possibilitaram que as mulheres quadrinistas tivessem maiores oportunidades para divulgarem e venderem trabalhos cujas histórias mais complexas de personagens femininas eram, pela primeira vez, produzidas por mulheres. Assim, vinte e uns anos depois da $19^{\mathrm{a}}$ Emenda Constitucional, que garantia à mulher norte-americana o direito ao voto, nasceu a super-heroína Miss Fury que,

\footnotetext{
6 "If all the women of the world got together, there wouldn't be any more wars."
} 
como várias outras produções quadrinísticas do mesmo período (década de 1940), contribuía para encorajar a nova mulher a assumir posturas e responsabilidades consideradas até então como tipicamente masculinas.

Essa tomada de atitude em relação à promoção da autonomia das mulheres estava em afinidade com os desdobramentos da Segunda Guerra Mundial, que requisitava a força masculina para os campos de batalha. As mulheres eram solicitadas a desempenharem as funções daqueles que foram para a guerra. Assim,

[e]nquanto as forças armadas encheram suas posições com mão de obra masculina, a indústria encheu seus cargos com mão de obra feminina. Durante a guerra, o governo dos EUA e a indústria cortejaram mulheres americanas a trabalhar no esforço de guerra em âmbito interno (COLMAN, 1995, p. 15, tradução minha) ${ }^{7}$.

Como apontado anteriormente, Miss Fury foi a primeira super-heroína criada, roteirizada e desenhada por uma mulher num momento de efervescência das transformações políticas e socioculturais que envolviam as mulheres. Trata-se de uma obra que reflete grande parte das contradições vivenciadas pelas mulheres da década de 1940. A obra é ambivalente, marcada pela ideia de ruptura e continuidade com os valores da época no que toca às questões de gênero. As rupturas possibilitaram às personagens de Miss Fury novas experiências heroicas reservadas aos homens e a chance de (re) construírem a si mesmas, de avançarem e expandirem as possibilidades de atuação e vivência enquanto mulheres. As continuidades, por sua vez, preservaram traços fortes do mundo patriarcal e machista que realinha as mulheres em uma prisão repaginada: a moda, a beleza e, é claro, a família.

Considerando as visões de mundo sobre as identidades de gênero daquele momento, Miss Fury pode ser interpretada como uma produção que versa sobre a "nova mulher" - já não mais representada exclusivamente no ambiente doméstico - que ocupa posições sociais que distam dos cuidados para com o lar e a família. A noção de "nova mulher" começou a se constituir a partir da década de 1920 e se tornou temática recorrente também em produções da década de 1940, período de crescentes debates acerca dos direitos das mulheres sobre o próprio corpo, o que inclui o controle de natalidade e o direito ao aborto, encabeçados especialmente

\footnotetext{
7 “"[a]s the armed forces filled its ranks with manpower, industry filled its jobs with womanpower. For the duration of war, the U. S. government and industry wooed American women to work in the war effort on the home front".
} 
pela feminista Margaret Sanger $^{8}$, que vinha batalhando desde 1912 para garantir à mulher tais direitos.

No interior das produções quadrinísticas, a "nova mulher" foi descrita como indivíduos que conseguiram conquistar um espaço no mercado de trabalho, mas sem ofuscar os homens. Tratava-se de moças casadoiras que trabalhavam como secretárias ou modelos para ajudarem no sustento da casa e para presentearem-se com luxos. Ou seja, trabalhavam para comprar bolsas, sapatos e vestidos. Normalmente, quando encontravam um marido, o trabalho era abandonado para que pudessem se dedicar às demandas da casa e da família (HORN, 1997).

Miss Fury, de certa forma, destoa um pouco dos modelos femininos descritos acima. Mills teceu em sua obra personagens femininas relativamente mais fortes, determinadas, conscientes do "poder feminino" e que não estavam vinculadas ao ambiente doméstico; elas eram normalmente enfermeiras, espiãs, guerrilheiras, estilistas ou modelos. Até mesmo a ingênua personagem Lorel, moça casadoira de umas das tramas de 1952, não aceitou o destino traçado pela família e preferiu fugir de casa a se casar com o homem que havia sido escolhido para ela.

Há em toda obra de Mills pelo menos oito mulheres com participações significativas e com características bastante peculiares. São elas: Marla Drake /Miss Fury, Francine, senhora Grace James Dana, baronesa Erica Von Kampf, Miss Lind, Era, Doreen e Belle. Todas essas mulheres desenvolveram funções importantes e seguiram em afinidade comportamental e de estilo com as personagens principais, Marla Drake e Erica Van Kampf. Com exceção de Francine, todas as personagens femininas, em algum momento da trama, foram vítimas de violência masculina ou sofreram algum tipo de intimidação por um ou vários homens. Essa questão reforça o argumento de Beauvoir que diz que "a violência cometida contra outrem é a afirmação mais evidente da alteridade desse outrem" (BEAUVOIR, 2016, p. 109), uma vez que quando o homem exerce algum tipo de violência, física ou simbólica, sobre a mulher ele reafirma sua imaginada superioridade em relação à mesma. Para cumprir com o propósito de responder em que medida Miss Fury subverte o modelo estabelecido de produção de quadrinhos de super-heróis e, por conseguinte, da representação da figura feminina considerarei somente aquelas personagens que tiveram maior destaque na obra: Erica, Era e Marla Drake/Miss Fury.

A vilã, baronesa Erica Von Kampf, provavelmente é a personagem feminina favorita de Tarpé Mills, segundo Robbins (2012, p. 10). Ela é uma espiã alemã, ambiciosa, que corresponde

\footnotetext{
${ }^{8}$ Margaret Sanger era tia de Olive Byrne, uma das amantes e possível inspiração de Marston, o criador de Mulher Maravilha.
} 
aos estereótipos da típica femme fatale ${ }^{9}$ que faz uso da beleza e da esperteza para conseguir o que quer de um homem. Ela só não é páreo para o principal homem vilão, o general Bruno, que é, ao mesmo tempo, seu maior algoz e sua maior paixão (ROBBINS, 2012, p.09). A baronesa é talvez a mulher mais sensualizada em Miss Fury - dos vestidos às lingeries, Erica esbanja sofisticação - e, seguramente, é também a mais violenta e a mais violentada. De 1941 a 1944, há pelo menos cinco cenas fortes de Erica sofrendo algum tipo de violência, mas, sem dúvida, a mais aterradora foi quando ela foi coisificada - marcada a ferro em brasa com o símbolo da suástica na testa como uma punição por desavenças com os irmãos Manero, argentinos e também vilões da trama.

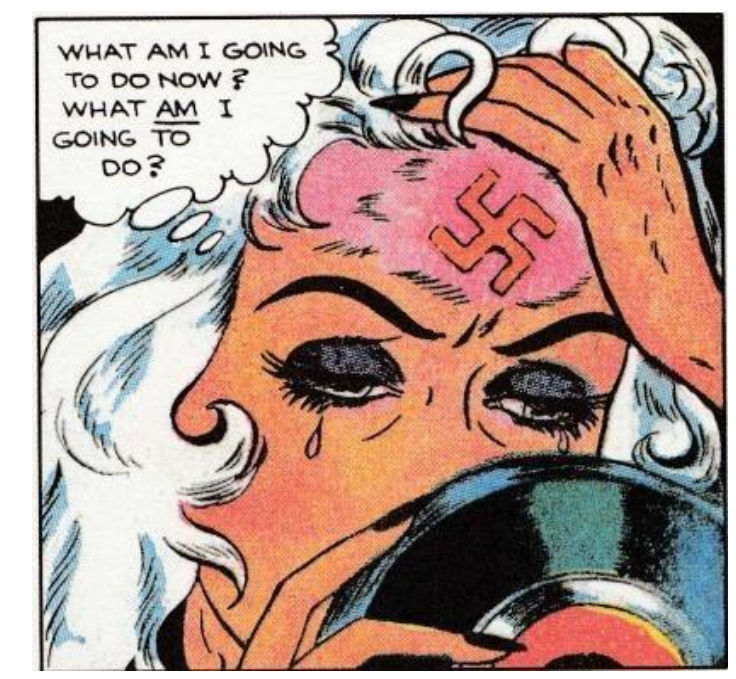

Figura 1 - Erica. Disponível em: MF1, 2013, p. 71.

Ao contrário das outras mulheres apresentadas na produção quadrinística, Erica está sempre dependente financeiramente de um homem. Ela quer o mais rico, aquele que lhe oferece melhores possibilidades de ascensão e é capaz dos atos mais torpes para conseguir. Ela se tornou mãe de um menino, fruto de um relacionamento interesseiro com o ex-noivo de Marla Drake, Gary Hale. Como o filho não convinha aos seus propósitos naquele período, Erica, que já estava separada de Gary, deixou a criança ainda com três meses de idade nas mãos de um médico cientista louco, Diman Saraf, que realizava experimentos em pessoas, inclusive no bebê, e com quem ela prometera se casar em breve. Erica só reencontrou o filho quando o mesmo já estava

\footnotetext{
${ }^{9}$ Femme fatale significa literalmente "mulher fatal". O termo se refere a mulheres belas, sensuais e elegantes que representam perigos emocionais e/ou físicos para suas vítimas, normalmente homens (JABER, 2016).
} 
com dois anos, momento em que ela passou a enxergar nele a possibilidade de conseguir a fortuna do ex-marido, Gary, que sequer sabia da existência do filho.

Erica era uma pessoa verdadeiramente ambígua que não conseguia manifestar nenhum sentimento de afeto pelo filho, nem por qualquer outra pessoa. É importante dizer que ela era espiã do governo nazista, atividade que conciliava com seus interesses pessoais de fortuna fácil. Mas sentia arrependimento por ter deixado o bebê aos cuidados de Diman. A criança não existia legalmente, uma vez que não foi registrada, e também sequer recebeu um nome daqueles que a criaram. Fora apenas chamada vez ou outra por Erica, mas longe da criança, como Gary Hale Jr. por conta da semelhança física entre pai e filho.

A baronesa Erica Van Kampf, por toda a trama, muda o estilo de acordo com a moda, muda os interesses, os parceiros sexuais, mas sempre permanece como a super femme fatale.

A brasileira e guerrilheira Era (Fig. 02) - uma figura exótica que se assemelhava à Carmem Miranda, segundo Robbins (2012, p. 10) - é outra mulher marcante na trama. Ela é livre de amarras sociais, é bela, forte, decidida, destemida e é também a chefe dos guerrilheiros brasileiros e argentinos que se mobilizavam no intuito de proteger o Brasil dos nazistas, representados em Miss Fury pelo exército comandado por general Bruno, que já estavam no país com a intenção de dominá-lo. Consciente da sua beleza e da sua força, ela era sempre loquaz com aqueles com quem não queria estabelecer contatos íntimos. O escolhido para ser seu parceiro foi o argentino Chico e todos aqueles, principalmente aquelas, que ousassem interferir em seu relacionamento com Chico sentiriam a força da sua ira. Era, que poderia perfeitamente ser a Miss Fury de Tarpé Mills, é pouco retratada na obra e quando isso acontece ela não ostenta o glamour excessivo característico de Marla ou da baronesa Erica. Contudo, é tão sensualizada quanto qualquer personagem feminina retratada na obra.

Na tirinha de número 293 (2012, p. 156), Era aparece em Nova Iorque trabalhando como dançarina, ao estilo Eva (Fig. 03), como uma forma de ganhar dinheiro ao mesmo tempo em que tenta reencontrar seu grande amor, Chico, que havia desaparecido no Brasil durante a guerra. A referida tirinha foi censurada na época por ser considerada depravada (ROBBINS, 2012, p. 11). 


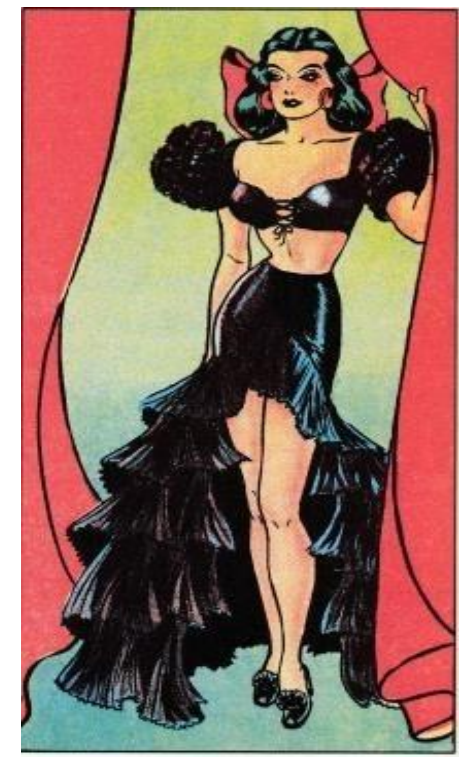

Figura 2- Era. Disponível em: MF2, 2012 p. 156.

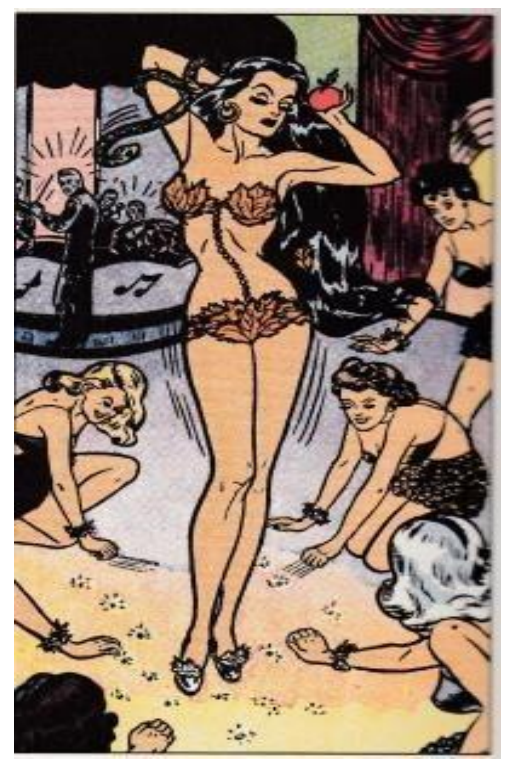

Figura 3- Era. Disponível em: MF1, 2013, p. 114.

Depois de muitas tentativas, Era reencontra seu grande amor no dia do seu casamento com o milionário Thebold - que usufruía dos efeitos de uma poção da juventude da qual fazia uso. Mesmo com tudo pronto para o casamento, ela não ignorou a oportunidade de ser feliz ao lado de Chico, desistiu de se casar com Thebold e retornou ao Brasil. Esta foi a última vez que Era apareceu nos quadrinhos.

Marla Drake, a personagem principal da obra, é jovem, solteira, rica e independente. Vivia só, sem a interferência de pai, marido ou irmão, tendo como companhia a criada, um gato e, por vezes, o porteiro. A desenvoltura de Marla Drake falava às mulheres de seu tempo - seja enquanto senhorita Drake, seja enquanto Miss Fury, pois se tratava de uma mulher forte e decidida, assim como a personagem Era. A presença dessas mulheres fortes como Marla Drake nos permite inferir que a produção de Mills pode ser interpretada como uma analogia à mudança social perpetrada pelas mulheres norte-americanas daquela época (NOGUEIRA, 2015).

Autossuficiente, Marla Drake não precisava de superpoderes nem de um homem para resolver seus problemas. Ela se garantia em suas catfights e salvava a vida de vários amigos: Era de um incêndio, Daniel Carey de ser morto pelo exército do general Bruno, Gary Hale dos comparsas do médico cientista Diman, e Delvin, de ser condenado por um crime que não cometeu. Marla ainda sabia pilotar avião, manejar armas, era inteligente, sabia sair de muitos problemas sem lançar mão de atos violentos e ainda se tornou mãe adotiva num período que ser mãe solteira era considerado algo inaceitável. 
Contudo, é fato também que seu comportamento estava em sintonia com os discursos que conferiam à mulher a disponibilidade à formação familiar e à feminilidade. Marla Drake desejava constituir uma família com o inseguro Gary Hale. Na tirinha de número 54, de 12 de abril de 1942, por exemplo, decidida a solucionar um mal-entendido com seu noivo, embarcou para o Brasil com todo o enxoval e pronta para se casar. Evento que nunca se concretizou.

Marla também era apegada à moda e à beleza e onde quer que fosse havia sempre o guarda-roupa recheado com as peças de roupa mais finas, sapatos e produtos de maquiagem. Essa característica em especial nos remete à ideia da feminização do consumo (EWEN, 2001), que é estimulado principalmente pelos produtos da indústria cultural de massa: o cinema, a novela, a publicidade e até mesmo as histórias em quadrinhos que criaram e difundiram o conceito visual da mulher ideal e se esforçaram no afã de convencerem as mulheres a perseguirem este ideal.

Assim, as mulheres, ao internalizarem a ideia de que seriam valorizadas pela aparência/feminilidade, passaram a cultivar os atributos corporais, as vestimentas e outros adereços, tais como a maquiagem, a manicura, o corte de cabelo etc. para se aproximarem dos modelos considerados ideais e, assim, serem aceitas socialmente. Ao evidenciar tais preocupações em Miss Fury, Mills faz com que a "feminilidade" ganhe, às vezes, mais destaque do que o lado corajoso e destemido de Marla/Miss Fury. Reside nisso a ambiguidade a que aludimos antes.

Desta feita, desde a primeira tirinha Marla Drake/Miss Fury é apresentada de maneira bastante "feminina" e sensualizada. Neste sentido, vale relembrar que, no início da trama, lemos que Marla era atenta ao mundo da moda e às regras de etiqueta e, por isso, a jovem decidiu não mais ir a uma festa à fantasia porque fora informada de que havia outra pessoa, Carol, usando um traje idêntico ao dela. A preocupação com a aparência é uma constante em Miss Fury, assim como a sensualidade e o erotismo também são.

Esse diálogo com a sensualidade/erotismo produz dois efeitos de sentido; ora para empoderar a mulher - como se a beleza e a sensualidade fossem "armas femininas", ora para o simples deleite do público masculino como acontece, entre outros eventos, na catfight $^{10}$, a briga entre Marla Drake e Erica Von Kampf, na qual a personagem principal se encontra trajando roupas íntimas e Erica com um vertiginoso decote em seu robe; ou quando Era e Marla são retratadas descendo de paraquedas como se se tratassem de presentes dos céus para os soldados que se encontravam de mãos postas e ávidas para recebê-las (Fig. 04); ou ainda quando a autora

\footnotetext{
${ }^{10} \mathrm{O}$ termo catfight, cuja tradução literal seria "briga de gato", é utilizado para descrever brigas entre mulheres.
} 
propositalmente fecha a imagem em closes de partes do corpo feminino cuja intenção é realmente erotizar. Deste modo, ao representar as personagens femininas ressaltando a sensualidade, o glamour e a beleza, a quadrinista parece trabalhar em duas frentes: agradar aos leitores com as belas formas femininas e fornecer às leitoras modelos de mulheres que esbanjam boa aparência e feminilidade.
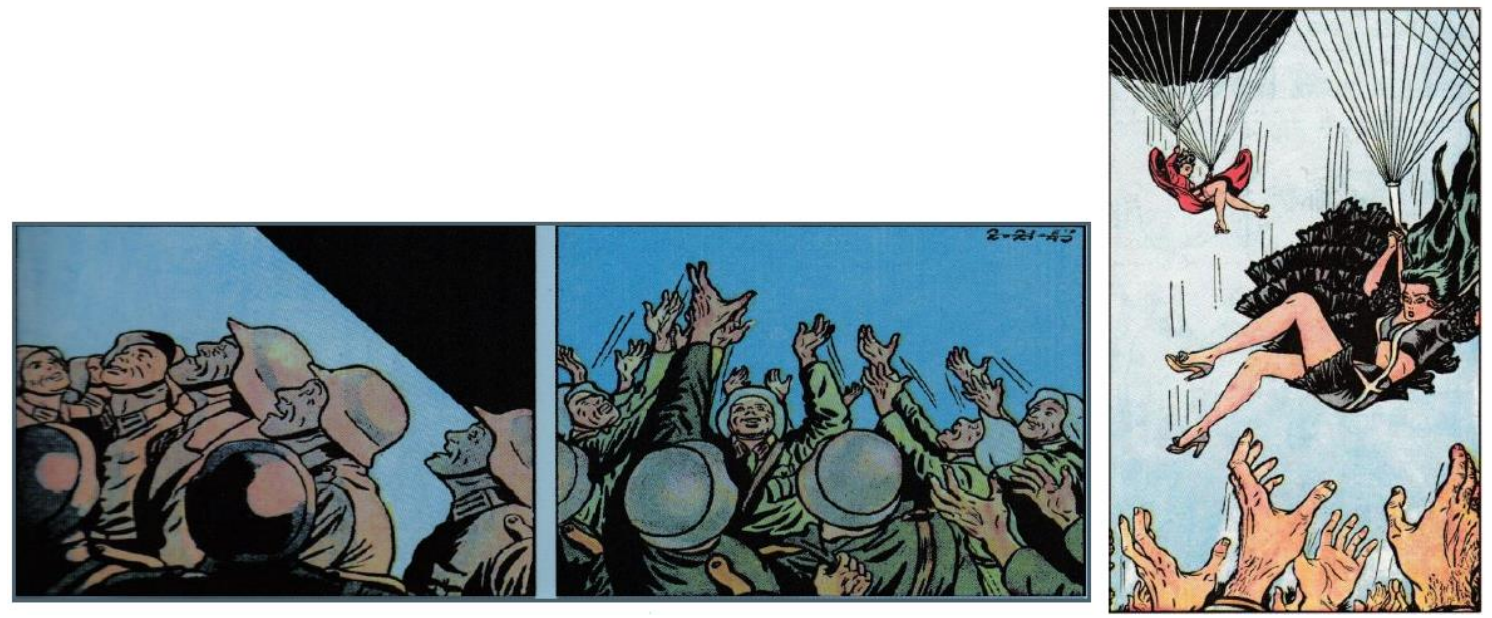

Figura 4 - Marla e Era descendo de paraquedas. Disponível em: MF1, 2013, p. 122.

Somados a esses eventos há vários outros em que Marla Drake e outras personagens mulheres são tratadas como objeto - evidência de que o corpo da mulher de papel e do homem de papel nas histórias em quadrinhos são construtos sociais permeados pelas experiências que atravessam as vivências reais. No entanto, é importante acrescentar que embora não existam cenas explícitas de sexo ou estupros em Miss Fury, há alusão à apropriação do corpo feminino pelos homens que as cercam. Nesse sentido, homens aparecem, beijam e objetificam mulheres sem que haja qualquer tipo de negociação ou consentimento. Tudo acontece como se elas existissem para atender aos desejos deles. Atitudes como essas não estão restritas aos vilões. Há momentos em que os "mocinhos" agem de forma semelhante - sinal de que o comportamento machista é uma questão estrutural. 

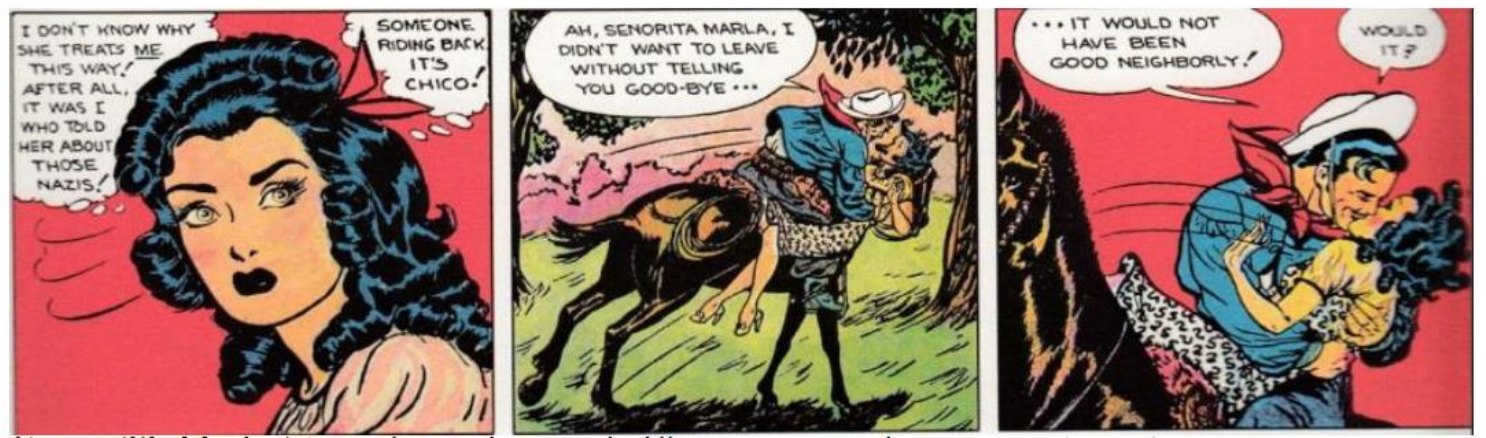

Figura 5- Marla é tomada nos braços de Chico, sem que haja consentimento. Disponível em: MF1, 2013, p. 92

Na tirinha 93, publicada em 10 de janeiro de 1943, há outro evento interessante em que há alusão à responsabilização feminina acerca dos comportamentos não consentidos do homem para com a mulher. Havia uma festa em comemoração ao sucesso dos guerrilheiros contra o exército do general Bruno. Chico, o argentino namorado de Era, convidou Marla para uma dança; Era ficou furiosa e decidiu interrompê-los. Após esse episódio, Fingers decidiu alertar Marla sobre os ciúmes de Era e que ela deveria manter distância de Chico. Marla iniciou seu argumento dizendo que não era culpa dela, mas foi interrompida por Fingers que disse: “Ah, pare! Vocês mulheres têm muitas maneiras de repelir um cara” (MF1, 2013, p. 116), ou seja, ele atribuiu à Marla a responsabilidade das investidas de Chico. O desenvolvimento da narrativa, se analisado a partir das dinâmicas sociais atuais, é desanimador, pois não houve qualquer problematização para este evento. Marla, com a fisionomia abatida, apenas desistiu da conversa, dando a entender que não valia a pena contra-argumentar; ela vai para o quarto de dormir aborrecida só para ser surpreendida por Era para outra catfight.

Considerando a época em que a autora produziu a referida história em quadrinho, faz sentido a ausência de debates que pudessem contribuir com a desconstrução ou problematização da forma como a mulher era percebida e tratada nos contextos privado e social. Naquele período, ainda não haviam sido organizados os debates acerca de legislações contra violência doméstica/sexual e assédio sexual, por exemplo. Tais discussões foram debatidas com profundidade somente vinte anos depois, com as lutas pela "liberação feminina" iniciadas na década de 1960.

A cuidadosa representação das personagens femininas trajando roupas elegantes, salto alto e maquiagem, mesmo quando estavam em situações cuja integridade física era mais urgente do que a aparência física, é uma questão recorrente em Miss Fury e, ao que parece, era o que fazia com que as leitoras fossem às bancas todo domingo, curiosas para verem os modelitos de suas personagens favoritas: Marla Drake e baronesa Erica Von Kampf. Trina Robbins afirma 
que o sucesso das vestimentas glamorosas das duas personagens aumentou o número de cartas à quadrinista solicitando a criação de paper dolls ${ }^{11}$ (ROBBINS, 2012, p. 06). As paper dolls se tornaram comuns em produções cuja intenção era cativar o público feminino.

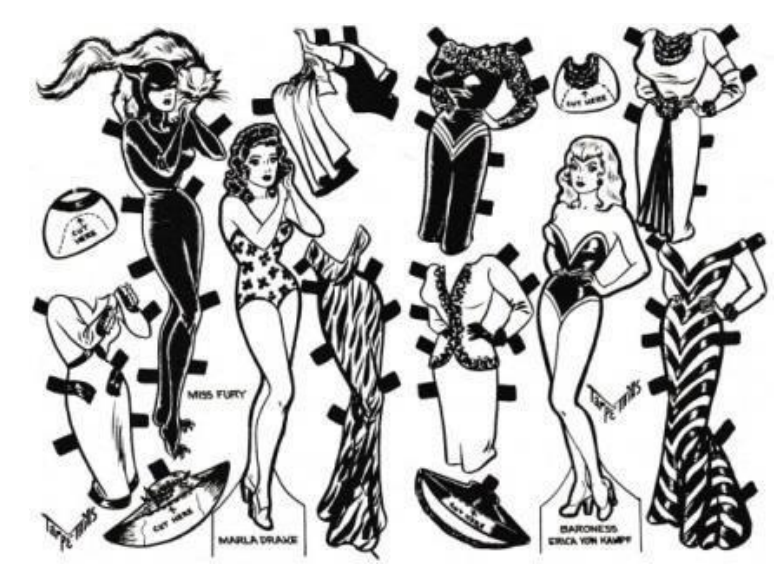

Figura 6 - Disponível em: MF1, 2013, p. 11.

Um episódio em especial, tirinha de número 68 publicada no dia 19 de julho de 1942, possibilita-nos algumas considerações sobre a relação entre a mulher e o rito da beleza, bem como sua função social. Ela ocorre quando Marla Drake estava no Brasil, acampada no meio da floresta e numa situação de tensão, uma vez que seus novos amigos estavam se preparando para um enfrentamento iminente contra o exército nazista no momento em que Marla e Era estavam se arrumando para saírem do quarto. Nessa tirinha, Marla estava diante de uma penteadeira improvisada se maquiando enquanto foi interpelada pela ciumenta Era: “Exatamente para quem está se embelezando?” (2013, p. 91). Esse questionamento nos direciona à discussão sobre a construção da ideia de que a preocupação feminina no que toca à beleza deve ser, sobretudo, uma preocupação para o outro, para o masculino, ou seja, a mulher passa a existir somente a partir da visão do outro. Nesse sentido, a provável mensagem presente na pergunta de Era seria: "para quem você está se arrumando?”, "Você quer ser notada por quem?" "Se for para Chico, desista porque ele já é meu".

A feminilidade associada à sensualidade em Miss Fury faz com que a separação entre vilãs e mocinhas, outrora tão aparente nos traços físicos e vestimentas (MORIN, 1997), passe a ter uma tênue diferença na produção de Tarpé Mills. O que realmente diferencia as vilãs das mocinhas nessa obra são as ações criminosas ou não; tanto heroínas quanto vilãs são muito glamorosas, bonitas, sensuais e determinadas a conseguirem o que querem. O que pode variar

\footnotetext{
${ }^{11}$ Paper dolls são figuras para recortar especialmente de homens, mulheres, roupas e acessórias. Ver Figura 06.
} 
no que diz respeito à estética são sutilezas como um laço no cabelo para transmitir um ar angelical, por exemplo (Fig. 07 e 09). Considerando esses aspectos, Morin (1997) afirma que

[...] a "virgem" e a vamp clássicas desapareceram para dar lugar a diversas variantes da good-bad girl, que herda a intensa erotização da vamp e a pureza da virgem. Essa imagem cinematográfica é a representação sublimada da mulher moderna: pintada e enfeitada como uma boneca do amor, mas buscando o grande amor, a ternura e a felicidade (MORIN, 1997, p. 145, grifos do autor).

A citação anterior delineia com precisão o perfil da personagem Marla Drake/Miss Fury e de quase todas as outras personagens das produções quadrinísticas do período pesquisado (década de 1940). A expressão good girls, ou good-bad girls, como Morin prefere adotar, é usada para se referir às (super) heroínas que, à imagem das pin-ups, estilo que foi bastante popular nos anos 1938-1954, rompem com a ideia de fragilidade, ingenuidade e submissão típica das personagens quadrinísticas produzidas antes dos anos 1920. As good-bad girls são fortes, sempre lutam bravamente e se metem em grandes encrencas para ajudar os mais fracos ou até mesmo o país, mas, com frequência, procuram um porto seguro afetivo, alguém para constituírem uma família quando a tormenta passar. E assim é Marla Drake, mesmo que a tormenta nunca passe para ela.

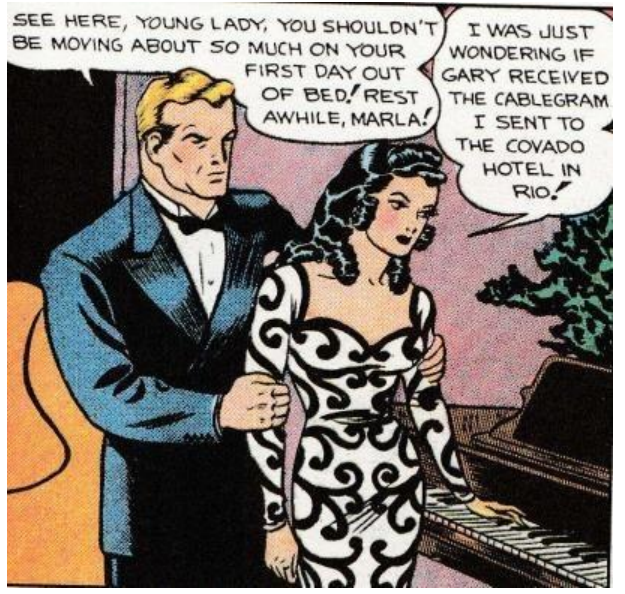

Figura 7 - Marla. Disponível em: MF1, 2013, p. 75.

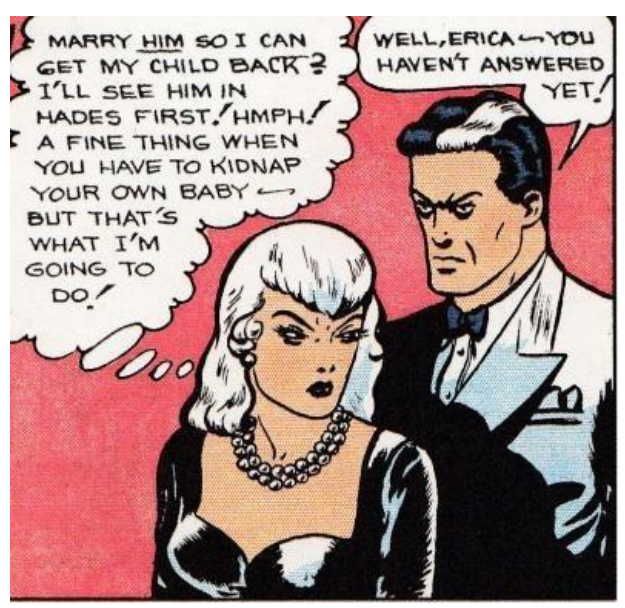

Figura 8 - Erica. Disponível em MF2, 2012, p. 76.

Contradições à parte, a posição de Marla Drake mais empoderadora se refere à questão da maternidade. Ainda no Brasil, logo após o fim da guerra, Marla se viu envolvida em sua antepenúltima aventura usando a pele de leopardo: o salvamento daquele que viria a ser seu 
filho adotivo - filho natural de Gary Hale e baronesa Erica Von Kampf, fato que Marla desconhecia completamente. O garoto estava prestes a ser imerso em um líquido desintegrador, uma invenção do médico cientista Diman Saraf para eliminar as evidências de seus crimes, quando Marla adentra no espaço destinado à realização de experimentos, trava uma luta corporal com o médico e um de seus comparsas, salva a criança e contribui para o fim da carreira criminosa dos mesmos, pois Diman, inconformado com a possibilidade de ir para a prisão se suicida e, encurralados, muitos dos seus cúmplices foram vítimas do líquido desintegrador.

Nessa operação, quase todos aqueles que sobreviveram não viram as ações da Miss Fury, o que garantiu maior segurança para que ela apresentasse a criança às autoridades e se identificasse como a pessoa que a havia salvado. Esse fato facilitaria o processo de adoção. Como já foi informado, a criança não havia sido registrada e também não havia evidências de quem seriam os pais. Neste caso, seu destino seria o orfanato. Desapontada pelo destino da criança, Marla se prontificou a adotá-la, mas, em primeira instância, teve esse direito negado por ser uma mulher solteira e estrangeira. Mas ela não desistiu, prolongou sua estadia no Brasil e entrou na justiça para conseguir o direito à adoção. Sua persistência foi recompensada e Marla deu o seu nome à criança, tornando-se mãe solteira de Darron Drake.
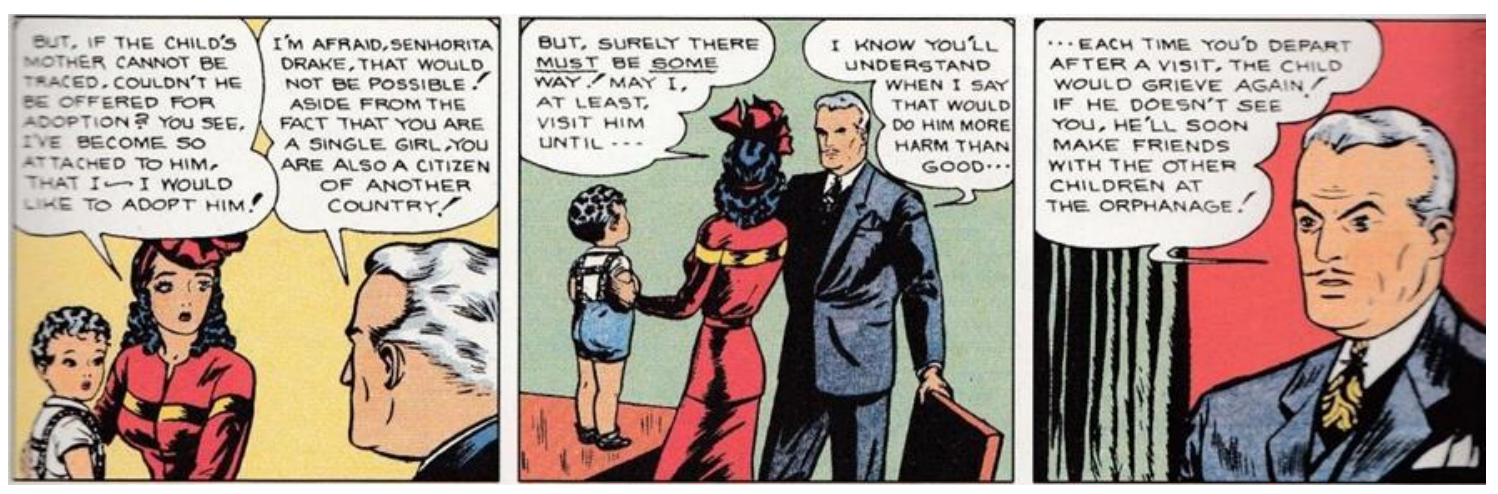

Figura 9- Da possibilidade de adoção. Disponível em: MF2, 2012, p. 75.

Nos 10 anos de Miss Fury, Marla Drake não se casou e a produção se encerrou quase como começou (ROBBINS, 2013): com Marla levando uma vida de aventuras, luxo, glamour, flertes e cuidados com o filho Darron Drake. Esse último foi a única grande mudança na vida de Marla. A pele de leopardo que era usada somente quando Marla julgava ser estritamente importante resguardar sua identidade quase desapareceu de cena - de 1944 a 1952, a persona Miss Fury, marcada pelo uso da pele de leopardo, apareceu apenas três vezes. 


\section{CONSIDERAÇÕES FINAIS}

A produção quadrinística Miss Fury (1941 - 1952) foi um artefato artístico criado num período de transformações sociais e culturais experimentado pelos EUA na metade do século XX. Neste período, com os homens americanos deixando seu país para lutarem na Segunda Guerra, o governo e a economia americana sentiram a necessidade de que as mulheres ocupassem os lugares tradicionalmente ocupados por eles. Para angariar números significativos de mulheres, o Office of War of Information (OWI) foi acionado para desenvolver propagandas que estimulassem mulheres a ocuparem os cargos vacantes.

As histórias em quadrinhos produzidas neste período contribuíram grandemente para incitarem as mulheres a atenderem o chamado do governo. Inspiradas pelo mote We can do it! (Nós conseguimos!, em português) as mulheres, tanto na vida pública como no interior dos quadrinhos, passaram a desempenhar papéis importantes como o de enfermeiras, pilotas, repórteres, espiãs e também de super-heroínas. É neste contexto que a super-heroína, objeto deste estudo, insere-se.

Miss Fury é o alterego de Marla Drake que, por sua vez, é fruto de uma sociedade em processo de (re) adequação da figura feminina, mas que é ainda uma sociedade conservadora, machista e que limita as atividades a serem desempenhadas por mulheres. No entanto, Marla é uma mulher que, em virtude das características que já ressaltei, pelo conhecimento que possui e pela posição social que ocupa, goza da liberdade de transitar por diferentes esferas e realizar atividades que eram atribuídas somente aos homens. Ela não demonstra em nenhum momento se sentir inconformada com a condição feminina. Ao contrário, parece se divertir com as normas sociais no que se refere à constituição familiar e à beleza, por exemplo. Um ponto singular da obra é que Marla não precisa da persona Miss Fury para lutar por aquilo que acredita ser o certo, ela só lança mãos da pele de leopardo quando quer proteger sua imagem de possíveis escândalos, por estar realizando atividades que não condizem com a imagem feminina aprovada socialmente e que ela escolheu representar.

Neste sentido, a beleza e a objetificação, especialmente a feminina, constituem-se o leitmotiv e, como pode ser notado pelas observações anteriores, Tarpé Mills não declinou de tais recursos. Ao contrário, sua produção maior circulou ao longo dos 10 anos de existência, ao mesmo tempo, dialogando e rompendo com os modelos de representação feminina nas produções quadrinísticas daquele período, década de 1940. Ou seja, a artista, consciente ou inconscientemente, brincou com a representação de homens e mulheres tanto no campo 
imagético quanto no interior da trama textual e, ao fazer isso, Tarpé tanto quebrou quanto reproduziu estereótipos.

\section{REFERÊNCIAS}

BEAUVOIR, Simone de. O segundo sexo: fatos e mitos. Tradução de Sérgio Millet. 3. ed. Vol. 1. Rio de Janeiro: Nova Fronteira, 2016.

COLMAN, Penny. Extraordinary Opportunities for Women: "Rosie the Riveter". In: COLMAN, Penny. Rosie the Riveter: Women Working on the Home Front in World War II. New York: Crown Publisher, 1995, p. 15-22.

COOGAN, Peter. Superhero: A Secret Origin of a Genre. United States of America: MonkeyBrain Books, 2006.

COOGAN, Peter. The Definition of a Superhero. In: HEER, Jeet; WORCESTER, Kent (Org.). A Comics Studies Reader. United Stated of America: University Press of Mississippi, 2009.

EWEN, Stuart. Captains of consciousness: advertising and the social roots of the consumer culture. New York: Basic Books, 2001.

HALL, Stuart. A identidade cultural na pós-modernidade. Tradução de Tomaz Tadeu da Silva e Guacira Lopes Louro. Rio de Janeiro: DP\&A, 2006.

HORN, Maurice. Women in the Comics. New York: Chelsea House Publisher, 1977.

JABER, Maysaa Husom. Criminal Femme Fatales in American Hardboiled Crime Fiction. New York: Palgrave Macmillan, 2016.

LEPORE, Jill. The Secret History of Wonder Woman. New York: Alfred A. Knopf, 2014.

MADRID, Mike. Vixens, Vamps and Vipers: Lost Villainesses of Golden Age Comics. United States of American: Exterminating Angels Press, 2014.

MADRID, Mike. The Supergirls: Fashion, Feminism, Fantasy and the History of Comic Book Heroines. New York: Exterminating Angel, 2010.

MORIN, Edgar. Culturas de massa no século XX: neurose. Tradução de Maura Ribeiro Sardinha. 9 ed. Rio de Janeiro: Forense Universitária, 1997, p. 139-147.

MORIN, Edgar. As estrelas de cinema. Tradução de Salvato Teles de Menezes e António Durão. Lisboa: Livros Horizontes, 1980.

NOGUEIRA, Natania Aparecida da Silva. As representações femininas nas histórias em quadrinhos Norte-Americanas: June Tarpé Mills e sua Miss Fury 1941-1952. 2015. 168f. 
Dissertação (Mestrado em História), Universidade Salgado de Oliveira, Rio de Janeiro, Niterói, 2015.

PEISS, Kathy. Hope in a Jar: the Making of America's Beauty Culture. Philadelphia: University of Pennsylvania Press, 2011.

ROBBINS, Trina (Org.). Tarpé Mills: Miss Fury: Sensational Sundays 1941-1944. San Diego: IDW Publishing, 2013.

ROBBINS, Trina (Org.). Tarpé Mills: Miss Fury: Sensational Sundays 1944-1949. Diego: IDW Publishing, 2012.

ROBBINS, Trina. The Great Women Superheroes. Northampton/Massachusetts: Kitchen Sink Press, 1996.

ROBBINS, Trina. Pretty in Ink: North American Women Cartoonists 1896-2013. Seatle: Fantagraphics Books, 2013.

STULLER, Jennifer. What Is a Female Superhero. In: COOGAN, Peter; ROSENBER Robins S. (Org.) What Is a Superhero. New York: Oxford University Press, 2013, p. 19-24. 